\title{
Institutions in the climate adaptation literature: a systematic literature review through the lens of the Institutional Analysis and Development framework
}

\author{
MATTEO ROGGERO* \\ ALEXANDER BISARO** \\ Global Climate Forum, Berlin, Germany \\ SERGIO VILLAMAYOR-TOMAS ${ }^{* * *}$ \\ ICTA, Autonomous University of Barcelona, Barcelona, Spain
}

Resource Economics Group, Humboldt Universität zu Berlin, Berlin, Germany

\begin{abstract}
Analyses of climate adaptation seldom rely on the conceptual toolbox of institutional economics. Yet articles addressing institutions make up a large portion of the climate adaptation literature. With a wealth of institutionally relevant knowledge in the adaptation literature, organizing such knowledge in institutionally meaningful ways can advance the present understanding of the link between institutions and adaptation. Knowing which aspects of this link are well researched, and where in contrast research gaps lie, can provide guidance to institutional economists interested in adaptation. We contribute to this through a systematic review of the adaptation literature, assessing the consideration adaptation scholars give to different elements of the Institutional Analysis and Development framework. Results show a strong focus on collective choice and on adaptation by public actors, with an emphasis on rules in use, social interactions and, to a lesser extent, attributes of the community. Research gaps rather encompass operational and constitutional choice, private adaptation, physical interactions and biophysical conditions.
\end{abstract}

\section{Introduction ${ }^{\dagger}$}

Institutional analysis has gained prominence in the study of environmental problems (Ostrom, 2009; Thiel et al., 2016). Within the economics profession, institutional analysis refers to a body of scholarly work characterized by a diverse and yet typical portfolio of models, theories and frameworks connected

\footnotetext{
*Email: matteo.mancini.roggero@gmail.com

**Email: sandy.bisaro@globalclimateforum.org

***Email: villamayortomas@gmail.com

$\dagger$ Supplementary material for this paper is available at: https://goo.gl/kb1kRm.
} 
with the legacy of thinkers such as (inter alia) Elinor Ostrom, Ronald Coase, Mancur Olson and Thorstein Veblen. Yet the same concept can be understood with reference to its study object: institutional analyses are those that address institutional phenomena, whatever conceptual and methodological toolbox they apply. The present paper focuses on the gap between these two perspectives, addressing those analyses of institutional phenomena that do not explicitly rely on the toolbox of the institutional economist. It does so by analysing the literature on climate adaptation, where analyses of institutional phenomena are plenty (Eakin, 2005; Hinkel and Bisaro, 2014) but formal institutional analyses are just a few.

Indeed, a few recent analyses of climate adaptation do rely on the conceptual and methodological toolbox of institutional economics (Abel et al., 2011; Cuevas, 2016; Huntjens et al., 2012; Oberlack, 2016; Roggero, 2015). Yet these few analyses stand against a much larger wealth of institutionally relevant knowledge scattered across the adaptation literature. Organizing such knowledge in institutionally meaningful ways, we argue, can advance the present understanding of the link between institutions and adaptation, providing guidance to institutional economics scholars interested in the topic. Knowing which aspects are well researched and where research gaps lie can direct sophisticated institutional analyses towards the former and more explorative efforts towards the latter. With that in mind, we raise the following research question: which aspects of institutional analysis play a role in the analysis of institutional phenomena within the climate adaptation literature?

To address this question, the paper systematically reviews the adaptation literature with reference to the institutional analysis and development framework (or IAD; see McGinnis, 2011; Ostrom, 2005), a meta-theoretical construct identifying and linking key elements in the analysis of institutions. The paper explores which aspects of the IAD are already granted substantial attention by adaptation scholars, and which ones belong instead to uncharted territories. It is structured as follows: section 2 introduces institutions, adaptation and previous attempts to explore adaptation through the lenses of the IAD; section 3 introduces and operationalizes the methodological approach; section 4 details the results of the analysis; sections 5 and 6 respectively provide a discussion and some concluding remarks.

\section{Insights from the literature}

\section{Institutions, collective action and the IAD Framework}

The present paper refers to institutions as conceptualized in institutional economics, leaving out of the scope concepts of institutions from sociology and political sciences (e.g. Hall and Taylor, 1996). Among institutional economists the debate on the essence of institutions (North, 1991; Searle, 2005) has been 
Figure 1. The IAD Framework

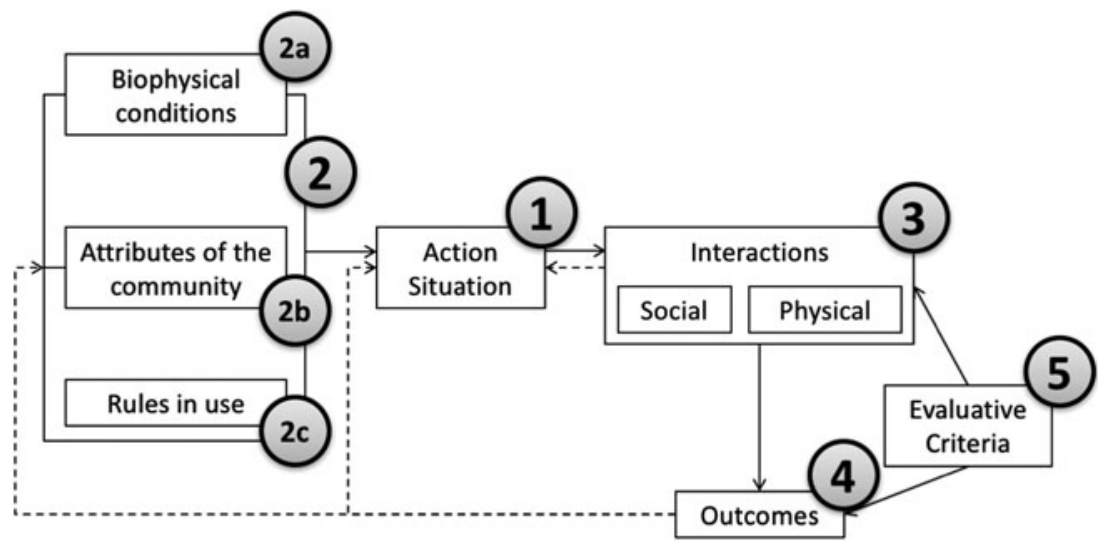

Source: Adapted from Ostrom, 1990.

intense and is still ongoing (Hindriks and Guala, 2015; Hodgson, 2015). In the following, institutions are understood as shared practices through which individuals address their mutual interdependencies (Paavola, 2007), attaching meaning and normativity to particular situations (Vatn, 2005). Laws, regulations, habits, customs, standard practices, professional codes, protocols, agreements, conventions, traditions, all represent institutions here, to the extent that they guide and shape individual behaviour in a social setting and regardless of their formal versus informal nature.

Institutions exist in order to address collective action problems. Key in understanding this is the concept of interdependent actors (Hagedorn, 2008; Paavola, 2007;). By shaping individual behaviour in a social context, institutions provide a degree of coordination and cooperation in order to overcome social dilemmas among actors that cannot achieve their own goals independently of one another. Not all institutional economists see social dilemma as the key rationale behind institutions (e.g. Knight, 1992). Yet such a perspective is central to the nature of the IAD (Ostrom, 1990).

The IAD framework has been developed in order to understand the ways institutions operate and change over time (McGinnis, 2011). Being a 'framework' it operates at meta-theoretical level, offering an umbrella under which multiple efforts to understand the institutional dimension of specific phenomena can be organized, facilitating meta-analytical and comparative work (Poteete and Ostrom, 2008). It spells out a set of working elements characterizing the analysis of collective action. These elements and their relationships have been described in detail by McGinnis (2011). For the reader's convenience, they are presented below and illustrated in Figure 1.

Figure 1 shows the action arena, with an action situation at its core (1), a set of contextual conditions influencing the action situation (2), a set of 
interactions in which action takes place (3), leading to certain outcomes (4), appraised by particular evaluation criteria (5) and ultimately feeding back to the initial conditions. Whenever describing any specific instance of collective action through these lenses, the action situation encapsulates the description of the agency dimension requiring the analyst to describe the actors at play and the set of alternative actions at their disposal.

The action situation is put in context through three specific contextual conditions, generally referred to as 'inputs' to the action situation. These are (2a) the biophysical conditions characterizing the action situation; (2b) the attributes of the community in which the action situation takes place; and $(2 \mathrm{c})$ the rules-inuse determining the allowable actions. This way, the IAD reminds the analysts to distinguish biophysical from social determinants of the action situation and to distinguish the pure description of such determinants from the description of the normative space in which actors and the analyst operate.

The collective or at least interpersonal dimension of the action situation becomes explicit with reference to the interactions that follow it. Here is room to distinguish physical and social interactions both from one another and as different phenomena than biophysical conditions and rules-in-use (Epstein et al., 2015). Physical interactions describe physical interdependencies among actors - interactions mediated by nature. Social interactions describe instead the processes and fora within which actors exchange information and ultimately make their individual decisions. Outcomes describe the individual and cumulative consequences of such individual decisions, whereas evaluative criteria encapsulate the way outcomes are looked upon by the analyst.

A certain ambiguity surrounds the role and understanding of evaluative criteria in the context of the IAD. McGinnis (2011) describes evaluative criteria as the way actors look upon the outcomes at stake. That would duplicate the behavioural assumptions describing the actor in the action situation, though. More convincingly, Ostrom (2011) refers here to the analyst's point of view. Such distinction is crucial: it is one thing to say that prisoners in a prisoner's dilemma aim at minimizing jail terms (as opposed to maximizing or satificing them); it is quite another thing say that the Nash equilibrium they will get to is suboptimal (or inefficient, unjust, unsustainable, etc.).

One last, important element of the IAD is the specification of the level of analysis. These are three: operational choice, collective choice and constitutional choice. Institutional analyses address constitutional choice whenever the action situation they refer to determines who is in a position to define specific rules shaping a given interdependency situation. They will instead address collective choice if they focus on the rules shaping the interdependency situation. Finally, if both rules and rule-makers are a given and the analyses pertain how to operate within the resulting institutions, the level of analysis is that of operational choice. The level of analysis is not explicit in Figure 1. The reason for this is that the same basic structure of IAD elements will apply to questions at any level of analysis. 


\section{Insights from the climate adaptation literature}

The study of climate adaptation addresses the many ways individuals, groups and society adjust to the prospective end of a stationary climate (Smit and Wandel, 2006). Linking climate adaptation with IAD reasoning, Hinkel and Bisaro (2016) define the 'adaptation situation' as the type of action situation adaptation that scholarship generally pertains to: one in which actors 'expect, perceive or experience climate impacts and adapt, thereby interacting with each other at various levels of decision-making' (Hinkel and Bisaro, 2016: 9). Three elements stand out in this definition, making the case for an institutional analysis: perceptions, experience and interactions. Conveniently, they relate directly to the four most important branches of the adaptation literature: vulnerability, learning, adaptive capacity and barriers to adaptation (Janssen et al., 2006).

Scholarly contributions on climate vulnerability address the link between climate impacts and their consequences for socio-ecological systems (Füssel and Klein, 2006). They are important here because, despite a certain ambiguity (O'Brien et al., 2011), they firmly underpin the centrality of the human factor in adaptation endeavours, seeing vulnerability as 'embedded in complex relations of power, resource distribution, knowledge and technological development' (Eakin, 2005: 1924). Adapting to changing climate conditions is thus a product of the way society distributes entitlements to different groups, including the poor and marginalized. Institutional economics, addressing how societies distribute entitlements (and obligations), can thus shed light on the determinants of climate vulnerability.

The branch of the adaptation scholarship addressing learning (Baird et al., 2014; Nguyen et al., 2016) arguably has its roots in adaptive management and social learning scholarship (Janssen et al., 2006; Pahl-Wostl, 2007), which advocates a deeper understanding of the way environmental problems are framed, shaping the subsequent choice among different solutions (Cundill, 2010; Pahl-Wostl et al., 2008). These contributions have paved the way for exploring the cognitive dimension of climate adaptation (Grothmann and Patt, 2005; Seara et al., 2016). Institutions provide socially warranted meaning to individual action (Denzau and North, 1994; Knight and North, 1997), they thus determine how individuals perceive problems (including climate change) and link them to potential solutions (including adaptation).

Adaptive capacity, the ability of individuals and groups to adapt to climate change, plays a key role in the concept of vulnerability and is, in turn, closely related to learning (Armitage et al., 2011). Its contributions to an institutional perspective thus overlap with the two literature branches introduced above. Yet there is an additional and quite central contribution: the emphasis on the ability of individuals and communities to act collectively to adapt to climate change (Adger, 2003; Pelling and High, 2005). From an institutional perspective, the value added thus focuses on requirements and conditions for collective action and institutional change. 
Finally, under the header of barriers to adaptation (Biesbroek et al., 2014; Eisenack et al., 2014), adaptation scholars point at specific interaction problems. Scholars stress dimensions such as poor interplay (Juhola and Westerhoff, 2011), inadequate rules and procedures (Jantarasami et al., 2010), limited cooperation (Glaas et al., 2010) or conflicting understandings (Harries and Penning-Rowsell, 2011). Oberlack (2016) identifies 31 such 'institutional barriers', grouped in the IAD-related categories of agency, social interactions and inherent (institutional) attributes. By referring to institutional mechanisms, the barriers literature delivers the strongest case for the institutional analysis of climate adaptation one in which the analysis of the specific attributes of given coordination structures sheds light on problematic and/or counterintuitive adaptation outcomes.

In summary, a few key messages can be drawn from the above. Institutions are at the core of those processes and practices determining human vulnerability to climate change. Institutions are also crucial for the way such vulnerability is being acted upon, shaping both the way individuals perceive and frame the adaptation situation they are in (learning) and their ability to adapt collectively (adaptive capacity). Finally, different coordination and cooperation problems emerge from the way actors interact to achieve adaptation (barriers). Across the different branches of the adaptation literature, it is thus possible to identify four different narratives - four complementary but different accounts of how institutional attributes are linked with different characteristics of the adaptation situation defined by Hinkel and Bisaro (2016). Figure 2 illustrates this in a schematic way.

Figure 2 doesn't do justice to the nuances of the adaptation literature, nor does it reflect its many ambiguities and present debates. Yet it provides a crisp point of departure for our analysis. Individual narratives therein constitute a specific, stylized mechanism through which institutions and adaptation link with one another. Conveniently, narratives are sufficiently crisp to allow for a link with the concept of 'evaluative criteria' as understood in the IAD: the way analysts looks upon the outcomes of the social interactions at stake.

Looking at the narratives as evaluative criteria has practical implications, since they will constitute the classes along which the articles will be clustered. This will take place on the basis of the articles' evaluative criteria. Articles addressing whether adaptation does or does not take place, making the manifestation of adaptation as a function of available institutions their core evaluative criterion, reveal an underlying narrative similar to the one sketched above with reference to the barriers literature. Articles focusing on whether or not collective action takes place, considering that as a precondition to adaptation, fall within the narrative emerging from the adaptive capacity literature. Similarly, articles addressing how status quo institutions shape vulnerability constitute instances of the namesake narrative, whereas articles exploring adaptation as a function of cognitive processes fall within the sort of narrative characterizing the learning literature. 
Figure 2. Stylized narratives within the adaptation literature

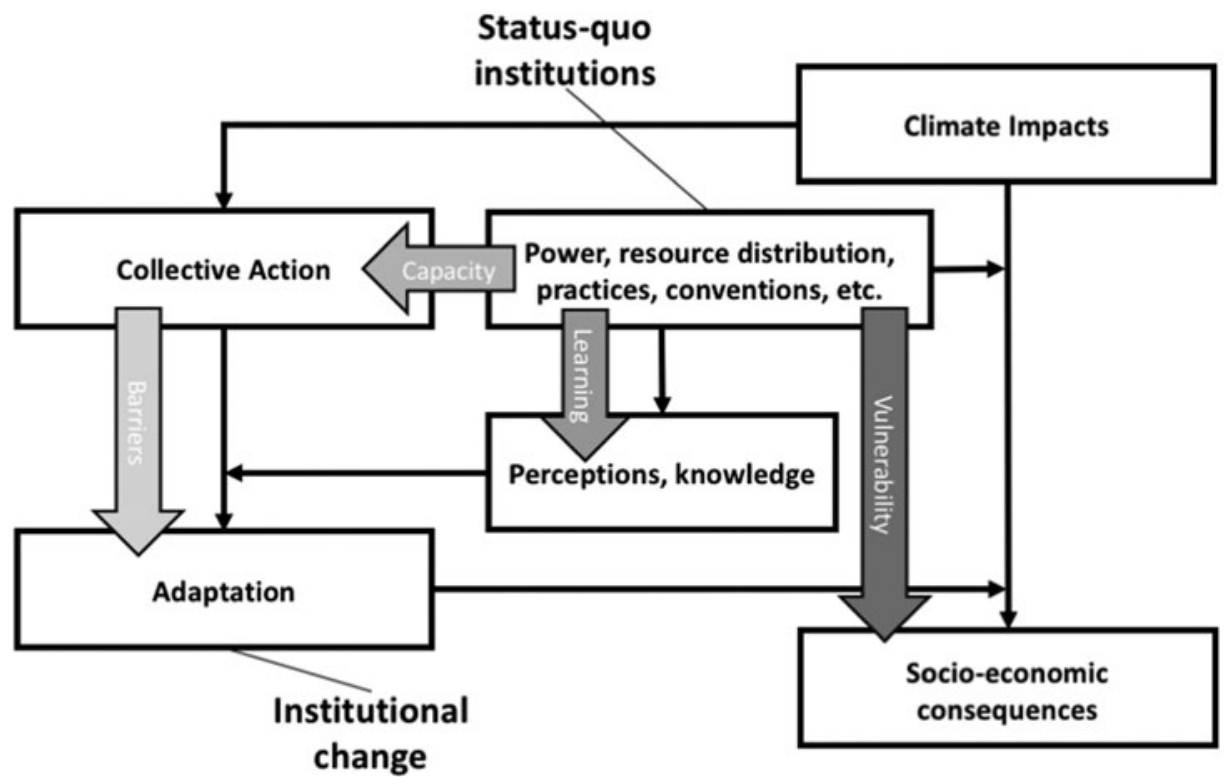

That said, it is also important to stress the rationale for distinguishing narratives from the actual branches of the adaptation literature. Such rationale is twofold. First, it reflects the greater diversity within, and fluidity of boundaries between branches, which contrasts with the more stylized and clear-cut profile of the narratives needed for classification purposes. Second, branches inevitably reflect the labelling and wording of the articles, whereas we are interested in the articles' contents. An article may de facto fall within the learning narrative even though it was originally intended as a contribution to the adaptive capacity literature, for example. Distinguishing the narrative from the branch allows us to avoid such ambiguity, and to focus on the analytical dimension of the articles under review.

\section{The IAD in the climate adaptation literature}

The above has shown that the adaptation scholarship has a clear institutional dimension. Yet the toolbox of institutional economics is only slowly starting to emerge in this field, with contributions such as Abel et al. (2011), Cuevas (2016), Huntjens et al. (2012), and Roggero (2015). Matters of space prevent us from addressing all of them. We will therefore focus on the one contribution most relevant to the present endeavour: Oberlack (2016).

Based on institutional theory, the analysis by Oberlack (2016) searches the adaptation literature for evidence of the link between institutions and adaptations ('archetypes' or 'archetypical' barriers to adaptation), and organizes 
it in a multi-tiered taxonomy derived from the IAD. The link to the present paper lies both in the use of the IAD and in the systematic reviewing of the adaptation literature. A closer look is therefore due, and will help clarify key aspects of the present work, in particular the unit of analysis, the level of analysis and the inductive versus deductive dimension.

The unit of analysis in Oberlack (2016) is the 'archetype', whereas here it is the individual article. The difference is one between characterizing institutions themselves (Oberlack, 2016) and characterizing the analyses of such institutions. The two papers are thus fundamentally different, and complementary to one another: Oberlack (2016) finds indeed most archetypes in more than one article; yet articles differ widely concerning research interests and design, providing different support to the same archetype. In contrast, the present paper explores how articles differ concerning research interests and design.

A further, key element of Oberlack (2016) is the multi-tiered nature of the taxonomy developed, where three top-level categories are further articulated in multiple sub-categories. Analyses can be carried out at each tier - the question being which one is the most appropriate. The aim of Oberlack (2016) is to display the heterogeneity of archetypes at the highest feasible level of resolution given the available data, making it clear that the most nuanced tier is the one to go for. Here, the issue is instead whether it is more meaningful and fit-for-purpose to focus on the IAD elements, or whether they should be 'unpacked' further. The present analysis explicitly chooses not to: given the interdisciplinary character of the adaptation literature, it cannot be safely assumed that articles address IAD elements in such detail as to allow for more subtle distinctions.

Finally, let us consider which directions emerge from the inductive versus deductive nature of the analysis in Oberlack (2016). Oberlack (2016) derives its taxonomy (including the archetypes, representing its lowest tier) in an iterative process of coding, alternating inductive and deductive phases. Although perfectly valid, such an approach neglects those institutional attributes not considered in the articles reviewed. By contrast, it is extremely valuable from the perspective of this paper to know whether particular IAD elements weren't so far linked to adaptation. Such elements cannot be left out of scope, calling for a deductive approach.

\section{Materials and methods}

\section{Rationale and general research design}

We perform a systematic review of articles addressing the institutional dimension of climate adaptation. To do so, we analyse peer-reviewed journal articles in English published between 2010 and 2014 that provide empirical analyses of adaptation situations. We focus specifically on articles referenced in the adaptation chapters of the latest IPCC report and search therein for analyses 
that address institutions, identifying 128 articles and scanning them for IAD elements. The present section spells out the methodological steps leading to such selection: it introduces systematic reviews as a methodology; articulates the details of the research design employed; highlights similarities and differences with other systematic reviews; details the coding process; and finally provides an illustrative example of how one specific article was coded, showing what counted as evidence and why.

\section{Systematic reviews}

A 'systematic review' is a way of surveying scientific literature. Common in health studies, systematic reviews have recently experienced a surge in popularity in the field of environmental studies, and particularly in climate research (Berrang-Ford et al., 2011; Bierbaum et al., 2013; Biesbroek et al., 2013; Eisenack et al., 2012; Ford et al., 2011; Ford et al., 2015; Nielsen and D'haen, 2014; Plummer et al., 2012). The systematic element refers to the ambition of synthesizing a specific body of literature without biases in the way articles are selected and looked at. This is achieved by selecting articles in a stepwise, transparent and reproducible way (Petticrew and Roberts, 2008).

Berrang-Ford et al. (2015) provide an overview of systematic reviews in the field of climate adaptation and find 27 such endeavours. Surprisingly, they find a large degree of heterogeneity in the way reviews are carried out. In their words, 'for systematic reviews, there is no "one size fits all"' (Berrang-Ford et al., 2015: 758). In the absence of a standard systematic review methodology, a suitable approach is to acknowledge the number of far-reaching research design choices involved in the process and make them as transparent as possible. With this in mind, the following subsections illustrate all the steps involved in the present review and link them with those in similar reviews, highlighting how the underlying design choices stand against the heterogeneity of the literature. Three aspects in particular will be highlighted: the approach to false negatives; the role of time; and the deductive versus inductive dimension of the analysis.

\section{Specificities of the present analysis}

\section{False negatives}

Systematic reviews generally identify articles for review through a combination of automated database queries and manual filtering. Concerning databases, articles diverge in terms of what is being searched: single databases (Berrang-Ford et al., 2011; Ford et al., 2011); multiple databases (Biesbroek et al., 2013; Kellens et al., 2013); individual journals (Nielsen and D'haen, 2014); personal article libraries (Plummer et al., 2012); or the internet (Ford et al., 2015). Filtering takes place iteratively, focusing first on titles, keywords and abstracts. In this context, false negatives represent those articles that were excluded on the basis of titles, 
keywords and abstracts, but should have been included because of their actual content.

For our purposes, false negatives are particularly problematic, since we address institutional analyses regardless of the conceptual toolbox they apply (and hence the keywords characterizing them). Institutions and adaptation mean different things to different people and not all relevant institutions and adaptations are actually called so. Filtering cannot avoid this situation without compromising the feasibility of a review, making a workaround necessary. Trying to avoid false negatives, the present paper identifies the primary set of articles by referring to the most recent IPCC Fifth Assessment Report from 2014. Specifically, the analysis focuses on articles that appeared in peer-reviewed scientific journals and were referenced in those chapters of the report addressing adaptation (chapters 141-7 of the Working Group II contribution).

The IPCC has an official mandate to 'provide policymakers with a clear view of the current state of scientific knowledge relevant to climate change' (IPCC, 2013a: 1). Relevance and quality are indeed the key criteria in the way IPCC authors are expected to deal with literature (IPCC, 2013b, appendix A: 17). It may still be far-fetched to view articles referenced in the adaptation chapters as the state of the art of adaptation research. Yet it seems safe to consider them at least as a representative subset of the current adaptation scholarship. If the literature reviewed in IPCC reports is at least representative of climate research, the adaptation chapters of the Fifth Report constitute a set of articles that are 'by definition' adaptation-relevant and can be further searched for in order to identify institutional analyses.

\section{The role of time}

Quantitatively, the Fifth Assessment Report references 1,124 peer-reviewed journal articles - still too many for a full text analysis. Berrang-Ford et al. (2015) stress that feasibility considerations may impose restrictions on the sources and/or sampling procedures. In the present case, a time restriction is imposed explicitly in order to avoid selecting articles based on titles, abstracts and keywords.

Compared to focusing on a single journal (e.g. Nielsen and D'haen, 2014) or extracting samples (e.g. Ford et al., 2015), restricting by time seems to be the safer choice. Ultimately, there is no reason to consider institutional analyses, for example from the year 2007 to take a systematically different consideration of IAD elements than those in 2013. The IAD was developed in the 1990s and already had meta-analytical purposes back then. If anything, the Nobel Prize awarded to Elinor Ostrom and Oliver Williamson in 2009 may have contributed to popularizing institutional economics from then on. Focusing on articles from 2010 to the present yields a set of 533 articles, which represents roughly half of the whole set and is sufficiently small to allow searching for institutional analyses based on the articles' full text. 


\section{Deduction versus induction}

The issue of induction versus deduction was raised above in connection with the different role of missing observations in the present analysis as opposed to Oberlack's (2016) one. Here, it is worthwhile to stress how the inductive versus deductive dimension of the study plays out in the context of a systematic review. In spite of their heterogeneity, systematic reviews tend to approach analysis and knowledge synthesis in inductive terms, striving for the 'bigger picture' emerging from the literature.

Berrang-Ford et al. (2015), however, find that self-reflection in these regards is often missing and that classifications seem more a product of prior knowledge than of an actual inductive process. Against this background, the present paper explicitly takes a chiefly deductive approach, interrogating the literature with a precise and operational research question in mind: whether articles grant consideration to the different elements of the IAD. Other systematic reviews with a deductive design are Nielsen and D'haen (2014) and Ford et al. (2015).

\section{Data collection and selection process}

The IPCC Fifth Assessment Report chapters on adaptation (chapters 141-7) reference 1,124 journal articles. Among those, articles dating between 2010 and 2014 amount to 533. From those, 15 articles appeared in journals to which the authors of the present paper have no institutional access. Requests sent to the corresponding authors received no replies. From those that were retrieved (518), articles such as purely theoretical contributions which did not constitute analyses of empirical materials were excluded.

The main rationale for such exclusion is based on the consideration that articles not foreseeing operationalization and data collection (such as conceptual contributions, but also letters, editorials, commentaries and book reviews) do not face the space restrictions that empirical articles have to deal with. As a rule of thumb, papers were excluded if they provided less than one page of empirical material. Similarly, meta-analyses were also excluded, as they encompass analyses of analyses and not analyses of particular circumstances. Secondary analyses of empirical materials produced elsewhere would have been allowed, but did not occur.

The above has led to a set of 336 articles among which to search for articles addressing institutions. Identifying articles addressing institutions was based on Hinkel and Bisaro (2014). They propose a classification of the adaptation literature based on the nature of the variables addressed, distinguishing impact analyses, behavioural analyses, institutional analyses and decision analyses. Impact analyses focus on the effects of changing climate conditions upon particular elements of the biophysical or socio-economic world, such as crops, soil fertility or the availability of particular resources. In contrast, behavioural analyses address how individuals and groups react to actual and/or perceived climatic changes. Decision analyses identify and compare different adaptation 
Figure 3. Article selection process

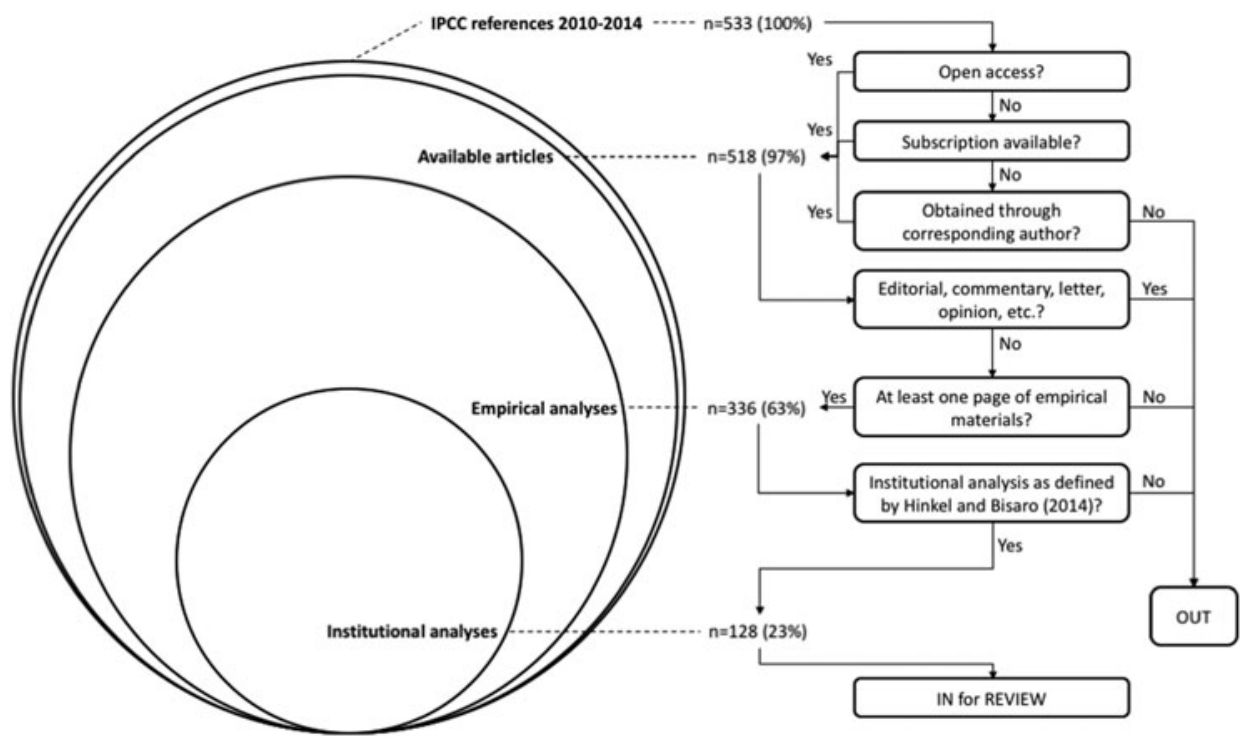

alternatives usually from a cost-benefit or multi-criteria perspective. Finally, institutional analyses explicitly address a set of institutions.

In line with the definition of institutions used here, articles counted as 'institutional analyses' if they addressed laws, schemes, conventions, shared practices, habits or traditions. Articles were excluded if they did not address human behaviour at all (e.g. Thackeray et al., 2010) or if they linked it directly to biophysical phenomena without reference to any institutional underpinning. Typical examples here are analyses linking vulnerability perceptions to willingness-to-pay for adaptation measures (e.g. Bichard and Kazmierczak, 2012) or analyses linking farming choices to changes in precipitation patterns (e.g. Zhang et al., 2013). Most certainly, institutions are at work in such situations, yet they are not explicitly analysed, making it impossible to consider such articles as institutional analyses.

The overall articles selection process is summarized in Figure 3.

\section{The coding process}

\section{General set-up}

The article selection process led to a manageable set of 128 items. That is remarkable: in a set of 336 articles providing empirical analyses of adaptation, more than one-third addresses institutions as defined herewith. Articles constituting institutional analyses were coded, with about $40 \%$ of the papers (53 of 128) assigned to two authors of this paper and coded independently in order to ensure interrater-reliability, with the rest being distributed among the 
authors of this paper individually. Between June 2015 and August 2016 several rounds of coding took place, allowing authors to discuss conflicting entries and possibly review their own coding, with reference to both conflicting entries and to those articles coded by a single author. In the last round, conflicting entries were eliminated through randomization.

While coding, IAD elements were distinguished between 'constitutive' and 'discretionary'. The rationale of such distinction is that IAD elements such as action situation, outcome and evaluative criteria are constitutive, even if sometimes implicitly, of any institutional analysis as understood here. Articles without an explicit action situation cannot be linked to institutions, whereas articles without an outcome cannot even be linked to adaptation. Articles without clear evaluative criteria do not address a problem (e.g. adaptation) at all.

We can thus assume that, among the articles reviewed here, 'constitutive' IAD elements are present by definition. Rather than searching for their presence/absence, constitutive elements were first retrieved qualitatively through open-text entries (that is: 'in words'). In a second step, these qualitative entries were classified in a narrower and more focused fashion through the following scheme: the action situation was used to distinguish public from private adaptation; outcomes determined the level of analysis (operational versus collective versus constitutional choice); evaluative criteria identified the type of adaptation narrative addressed (vulnerability versus learning versus adaptive capacity versus barriers to adaptation).

All other 'discretionary' IAD elements were coded for their presence/absence, distinguishing whether they were actually 'part of the analysis', whether they were only reported for illustrative purposes ('information provided'), or whether they were absent altogether ('not addressed'). For the reader's convenience, the resulting codebook can be found online in the supplementary materials.

\section{What counts as observation}

We now provide a practical illustration of the approach to coding by reviewing the coding of one particular paper (Biesbroek et al., 2010), chosen for its paradigmatic character. Biesbroek et al. (2010) compare national adaptation strategies (NAS) in Europe. An NAS constitutes a set of provisions shaping adaptation targets and responsibilities for actors at national and subnational levels in a country. It thus represents an institution, making Biesbroek et al. (2010) an 'institutional analysis' sensu Hinkel and Bisaro (2014). The paper is based on the extensive analysis of written materials and on semi-structured interviews, fulfilling the requirement of an 'empirical' analysis.

The paper addresses the action situation of national policymakers designing and implementing their respective NAS strategies, and is therefore coded as public adaptation. Regarding the level of analysis, the strategies constitute the outcome of the action situation: the paper deals thus with collective choice, in 
that it describes actors interacting so as to produce rules. This is most evident in the way the authors design their Figure 1, where the NAS is the outcome of 'Key drivers for adaptation policies' and 'Key facilitating factors for adaptation policies' (ibid.: 442). Finally, the key evaluative criterion for the analysis is whether the development of strategies is facilitated or not. Because of that, the article de facto addresses barriers to adaptation, even though the term 'barriers' hardly appears in the text and does not appear at all in title and keywords. This evaluative criterion is evident throughout the paper, but is best pinned down with reference to the article's focus on factors 'driving', 'facilitating' or 'motivating' the development of the NAS (ibid.: 443).

Moving to 'discretionary' IAD elements, Biesbroek et al. (2010) do not address biophysical conditions. They do stress that 'the selected countries represent the geographical spread of different types of climate impacts in Europe' (ibid.: 441), but this is a by-product of a research design choice which had other, more pragmatic criteria in mind: data accessibility (ibid.: 441). In other words, the paper does not leverage biophysical conditions as either a dependent or an independent variable or as a mediating factor. Biophysical conditions are therefore not part of the analysis, nor is any information on biophysical conditions provided, even for illustrative purposes. Europe's exposure to climate impacts features in the very first paragraph of the article, but is not further articulated in terms of the specific attributes of Europe's environment and how they actually differ across the countries at stake.

The same considerations hold for the attributes of the community: if the actors at the centre of the action situation are government officials, no reference is made to the community they belong to, be it in terms of the narrow community of government officials, the broader community of their respective nations, or Europe as a whole. In contrast, information is provided in terms of the rules-inuse and in terms of physical interdependencies. Concerning the rules-in-use, in the larger context of policy coordination, the articles provides some information about the institutions shaping the integration of the adaptation strategies with strategies and policies in other fields in certain countries (ibid., 446). Information is thus provided for illustrative purposes only, it doesn't make the rules-in-use a constitutive part of the analysis. Yet information is undeniably provided.

Similarly, the article shows how different policy sectors are considered (or not) in the various national adaptation strategies reviewed (ibid., 443: Table 2.). Introducing the cross-cutting dimension of the strategies implies physical interactions among different policy sectors and thus among the actors involved. On the other hand, differences therein are not further articulated, nor do they play a key role in the question whether they affect the process of developing national adaptation strategies. Claiming that physical interactions are part of the analysis in Biesbroek et al. (2010) is therefore inaccurate. Yet information is most certainly provided. By contrast, social interactions represent the core of the analysis, which is most explicit in sections 4,5 and 6. 
Figure 4. Descriptive statistics

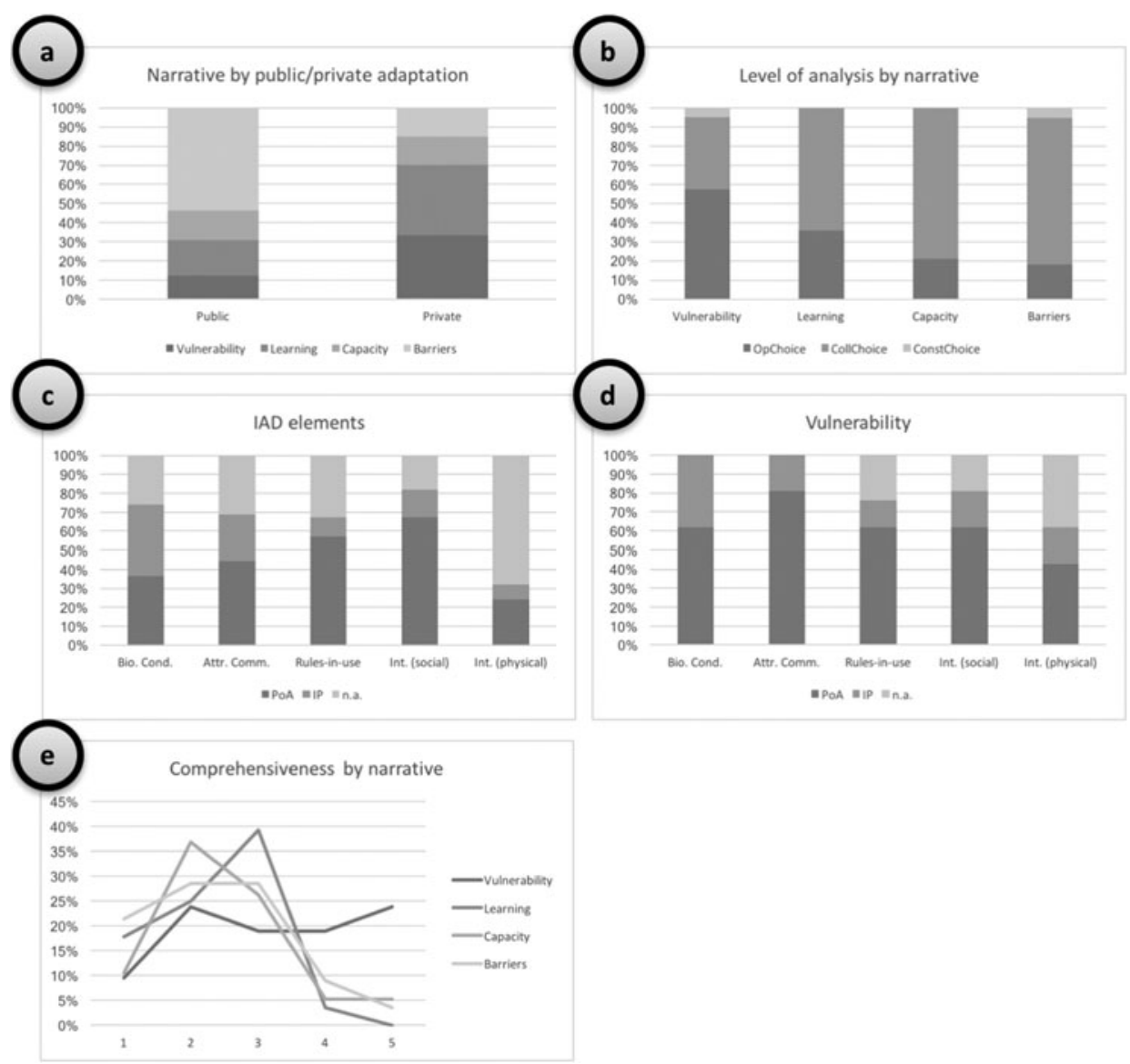

\section{Results}

By applying the coding procedure described above to the articles screened for review, a dataset was created, which we then analysed using basic descriptive statistics. Figure 4 displays the main results of such analysis, which are illustrated in detail in the remainder of this section.

\section{'Constitutive' IAD elements}

Our analysis begins by addressing 'constitutive' IAD elements. In terms of the public versus private character of the action situations addressed, articles tend to focus rather strongly on the former, with about five articles in six addressing adaptation by public actors. Concerning outcomes, the articles show a preference for collective-choice ones, which characterizes about two-thirds of the articles reviewed. Almost all remaining articles focus on operational choice, addressing 
how actors operate and adapt within those institutions in place. Institutional analyses of climate adaptation seem therefore to emphasize those processes leading to adaptation, rather than to the act of adapting itself. This is not surprising, and reflects the current state of adaptation 'on the ground', typically manifesting itself more in the form of plans and processes than in terms of actual adaptation (Berrang-Ford et al., 2011; Biesbroek et al., 2010). Constitutional choice, in contrast, is almost non-existent.

The emphasis on public adaptation may raise the suspicion that IPCCreferenced articles have a bias towards public actors, neglecting private adaptation. On a closer look, a more nuanced pattern emerges. Other types of analyses in the same set of IPCC-referenced articles (that is: impact analyses, behavioural analyses and decision analyses, provided they were not purely biophysical and had an empirical dimension) distribute evenly across the public/private divide $(55 \%$ public versus $45 \%$ private). Institutional analyses don't ( $78 \%$ public versus $22 \%$ private). The choice to address rules determining adaptation (constituting an institutional analysis) and the choice to focus on an action situation faced by public actors are thus clearly related.

It is certainly difficult to ascertain which way the causality goes - whether addressing rules leads scholars to focus on public actors, or whether addressing public actors leads scholars to focus on rules. It seems however reasonable to assume that the rules shaping private action situations are more difficult to spot for scholars without training in institutional economics, potentially leading towards different kinds of analysis (here: impact, behaviour or decision analysis).

If this is correct, rather than witnessing a bias of IPCC-referenced literature towards public action situations we are confronted with a research gap in the adaptation literature, which has so far neglected the institutional dimension of private adaptation. This represents a host of low-hanging fruit: a substantial amount of knowledge is already available from both behavioural and decision analyses, needing just to be complemented with an institutional perspective. With this amount of knowledge presently available it should be possible for institutional economists to fill the gap with very little effort.

Let us now turn to the narratives. Almost half of the articles (44\%) address how specific characteristics of the institutional arrangement in place hinder adaptation outcomes, and thus belong to the barriers narrative. The adaptive capacity narrative, focusing on how to adapt collectively, represents instead about $15 \%$ of the set: $16 \%$ of the articles address vulnerability and $22 \%$ can be ascribed to the learning narrative. The reader shall keep in mind that such narratives match only partially with the namesake branches of the adaptation literature. The adaptive capacity narrative, in particular, is defined in very restrictive terms (see section 2). These figures have therefore little to say about the size and relative importance of adaptive capacity, vulnerability, learning and barriers in the broader adaptation literature. They show instead how institutions and adaptation are linked to one another by adaptation scholars. 
Further insights can be gained by assessing how narratives differ in terms of their public/private dimension and the level of analysis. This is shown in Figure $4 \mathrm{a}$ and $4 \mathrm{~b}$, respectively. The former shows that public adaptation is dominated by the barriers narrative, whereas the learning perspective takes the lead concerning private adaptation. The latter shows that collective choice is the main concern across all types of narratives, with the sole exception of vulnerability articles, where almost two articles out of three address operational choice. Jointly, Figure $4 \mathrm{a}$ and Figure $4 \mathrm{~b}$ complement and further qualify the link between public/private adaptation and operational versus collective choice. The vulnerability narrative seems to drive the analysis of the operational-choice, mostly private dimension of adaptation. The closer the analysis gets to actual adaptation, the more it focuses on its public, collective-choice dimension.

\section{'Discretionary' IAD elements}

Turning now to the remaining elements of the IAD, the overall picture is one where each IAD element features individually in about 70 to $80 \%$ of the articles. Physical interactions constitute an exception to this pattern, appearing in only about $30 \%$ of the articles. Further insights can be gained by distinguishing whether IAD elements are addressed in analytical terms as opposed to being introduced for illustrative purposes. In that case, social interactions take the lead, as they are almost always 'part of the analysis', followed by the rules-inuse. Attributes of the community feature comparatively more often in purely illustrative, descriptive terms, whereas biophysical conditions do so almost half of the time. In comparison, physical interactions are featured mostly in analytical terms, if they are featured at all - see Figure $4 \mathrm{c}$.

If one controls for the type of narrative, the case for vulnerability is noteworthy (Figure $4 \mathrm{~d}, n=21$; the interested reader can refer to the supplementary material for the diagrams of the other narratives). Besides always including biophysical conditions, vulnerability articles address physical interactions almost twice as often as the rest. In general, articles tend to neglect physical interactions, which are almost negligible within the learning narrative. Vulnerability articles are a clear exception to that. Also noteworthy is the fact that attributes of the community, which are addressed in analytical terms in less than $50 \%$ of the articles reviewed are 'part of the analysis' in almost $80 \%$ of the vulnerability articles, taking the lead among IAD elements therein.

\section{Comprehensiveness}

After focusing on individual IAD elements, the analysis can turn to how the reviewed articles address several elements together. The rationale here is that articles may focus on few IAD elements, or they may address a comprehensive set of them. Both approaches are valid. Most importantly, though, the two approaches complement each other: sophisticated, in-depth analyses, for example of social interactions in a particular action situation, 
are likely to benefit from comprehensive analyses addressing the broader set of factors underneath the very same action situation. Conversely, comprehensive analyses touching upon all or almost all IAD elements will certainly benefit from sophisticated analyses exploring each element in depth. There are good reasons to have both. By the same token, research gaps emerge whenever either one is lacking.

In order to explore the comprehensiveness of the articles under review, we looked at the frequency of articles addressing respectively only one, two, three, four, or all five 'discretionary' IAD elements. Figure $4 \mathrm{e}$ does that for each of the four narratives. For simplicity, we refer here solely to IAD elements considered as 'part of the analysis' and leave out those appearing for illustrative purposes only. As the figure shows, most narratives peak between two and three IAD elements per article, and feature an almost negligible number of articles addressing four or five elements. The only exception here is the vulnerability narrative, where articles distribute in a fairly homogeneous way.

The near absence of articles covering all or almost all IAD elements is expected. Figure $4 \mathrm{c}$ shows the limited consideration articles have for physical interactions and (to a lesser degree) biophysical conditions, except for those falling into the vulnerability narrative (Figure $4 \mathrm{~d}$ ). If that is a feature of the adaptation literature, comprehensive analyses can cover at best three IAD elements: attributes of the community, rules-in-use and social interactions. In these regards, Figure 4e shows that a substantial amount of articles from all narratives do indeed address either all three elements or two out of three (in absolute terms, 37 and 35 articles respectively).

Articles focusing on only one IAD element are comparatively much fewer (21 in total), predominantly from the learning and barriers narratives. The question arises, whether they cover IAD elements homogeneously, or whether there is a bias towards any particular element. On a closer look, those articles focusing on only one IAD element strongly tend towards rules-in-use (52\%) and, to a lesser extent, social interactions (29\%). Biophysical conditions and attributes of the community get only a little consideration ( $14 \%$ and $5 \%$, respectively), whereas physical interactions get no consideration at all. This is expected, since these are typical traits of the vulnerability narrative, which hardly addresses IAD elements individually. The reader can find a diagram visualizing this distribution in the supplementary materials.

\section{Discussion}

\section{Summary of the results}

Several messages can be taken from the above:

- The largest block of articles is the one addressing public adaptation and collective choice, suggesting an emphasis on adaptation processes rather than 
on adaptation measures or adapted behaviour. Analyses here tend to address how institutional attributes hamper particular adaptation processes as in the barriers narrative, which characterizes about half of the articles reviewed.

- Analyses of private adaptation and operational choice questions tend not to address institutions, rather configuring decision analyses or behaviour analyses. If they address institutions, they tend to do so from a learning perspective (private adaptation) or from within the vulnerability narrative (operational choice). The choice of action situation seems thus to drive the type of analysis authors settle for.

- Among discretionary IAD elements, a first divide emerges between physical interactions, which feature rather seldom, and all other elements (biophysical conditions, attributes of the community, rules-in-use, social interactions), featuring rather often.

- A second divide emerges between elements featuring predominantly in analytical terms (rules-in-use; social interactions) and elements alternating analytical and illustrative roles (biophysical conditions; attributes of the community).

- Biophysical conditions and physical interactions play an important analytical role within the vulnerability narrative, but have a more limited role otherwise.

- Leaving biophysical conditions and physical interactions aside, articles cover well the three remaining IAD elements. All narratives provide a substantial amount of (limitedly) comprehensive analyses, addressing attributes of the community, rules-in-use and social interactions at the same time. Analyses addressing these three elements individually are however confined to the barriers and learning narrative, and hardly address the attributes of the community.

\section{Limits of the data collection and processing}

Before drawing lessons from the results above, it is important to review critically the potential biases and pitfalls inherent to the research design choices that led to them. Let us start from the inclusion and exclusion criteria. It has been argued that the choice to refer to an IPCC report as an authoritative source of 'adaptation literature' is not problematic. Instead, the way institutionally relevant articles were identified among them is worth exploring, particularly in light of a more restrictive definition of institutions compared with the very broad one used here. A more specific understanding of institutions would have reduced the number of articles for review. Given the dominance of codified rules, laws and hard arrangements addressed by the articles reviewed, different results could have only been achieved with a more explicit focus on habits and practices. That, in turn, would have restricted the analysis to vulnerability and learning issues.

Further critical reflections may address the way the collected data were interpreted. A limiting factor here is that being 'part of the analysis' still says very little about the actual consideration of the element at stake or the quality of the analysis. The same IAD element can be 'part of the analysis' in very different ways and to a very different extent, revealing a whole dimension of heterogeneity that 
is not addressed here. Limited space and resources precluded any engagement with more nuanced classifications. The caveat still holds, though, that articles do not always articulate their causal claims in a sufficiently clear way to allow for more nuanced classifications.

\section{Guidance for the institutional analysis of climate adaptation}

In order to provide guidance to institutional economists interested in adaptation research, we now link the above results to assets and trends in the institutional economics scholarship. Important parts of the institutional literature are concerned with the link between physical and institutional attributes of socio-ecological systems. For instance, the very IAD framework was later expanded into the SES framework (Ostrom, 2007) for the sake of taking biophysical considerations more explicitly into account (Vogt et al., 2015). From an institutional point of view, the limited consideration for biophysical conditions and physical interactions found here is thus very surprising. More importantly, it suggests a large potential for contributions from transaction costs economics (Hagedorn, 2008; Thiel et al., 2012; Williamson, 2000), and from the institutional fit literature (Cox, 2012; Young, 2002).

Our systematic review has also revealed a strong focus of the adaptation literature on collective choice. This suggests that the individual and operational (choice) aspects of adaptation have a comparatively thin institutional underpinning. There are thus important extensions to be made to the current contributions on the cognitive side of adaptation research, which do not often engage in analysis of the institutional environment within which individual actors operate. Whenever they do, analyses generally focus on vulnerability and learning. The operational choice dimensions of adaptive capacity and barriers to adaptation still await a thorough institutional treatment. There is scope for explorative contributions here.

Further guidance can be drawn by comparing the size of different narratives. The barriers narrative is certainly the most directly appealing to the institutional economist: by identifying factors that have detrimental effects upon adaptation, scholars clearly and explicitly point to institutional mechanisms where particular attributes of the governance arrangement in place either impede adaptation or lead to maladaptation. Articles addressing barriers are numerous. Institutional economists therefore have a large pool of information and cases to draw upon in order to deliver more sophisticated analyses of the institutional processes at play.

Yet adaptation is not just about barriers. Vulnerability articles show the highest proportion of truly comprehensive analyses (Figure 4e), providing the best coverage of biophysical conditions and physical interactions (Figure 4d), and the strongest interest in operational choice questions (Figure 4b). Institutional economists interested in how institutions determine vulnerability to climate impacts will therefore find materials addressing not only the way such institutions 
come about and change (collective choice) but also how actors operate within them (operational choice). These materials not only address rules-in-use and social interactions but also refer to community attributes, biophysical conditions and physical interactions, providing a good starting point for more sophisticated analyses of the different ways in which institutions determine vulnerability.

The adaptive capacity narrative is here defined as the capacity to act collectively for adaptation purposes. Conveniently, conditions for collective action are a well-studied topic (Poteete et al., 2010): the challenge for researchers interested in the institutional dimensions of adaptation is rather one of eliciting the specificities of climate adaptation therein. Exploratory approaches seem most appropriate here, complementing the largely available knowledge on social interactions and rules-in-use (see Figure5e) with insights on the role of biophysical conditions and physical interactions for collective action, which is currently lacking. Villamayor-Tomas (2017) does exactly that. More sophisticated analyses, if at all necessary, will first address the comparatively neglected role of the attributes of the community.

Finally, the learning narrative represents the entry point for private adaptation. In comparison, other narratives lack the private element almost entirely. Institutional analyses will be particularly convenient here given the host of behavioural analyses of adaptation available, and the affinity between institutional and behavioural economics. The most direct contribution would be one of unpacking analyses that currently link perceptions and knowledge issues directly to adaptation (here: behaviour analyses), and explore the institutional mechanisms at work there. Also, the learning narrative features a comparatively good balance between private and public adaptation, and between collective and operational choice. It is therefore the best candidate for explorative analyses crossing such divides.

\section{Conclusions}

Analyses of climate adaptation seldom rely on the conceptual toolbox of institutional economics. Yet articles addressing institutions make up a large portion of the adaptation literature. If there is a wealth of institutionally relevant knowledge in the adaptation literature, organizing such knowledge in institutionally meaningful ways can advance the present understanding of the link between institutions and adaptation, providing guidance to institutional economists interested in the topic. Knowing which aspects of such links are well-researched, and where instead research gaps lie, can direct sophisticated institutional analyses towards the former, and more explorative efforts towards the latter.

With this aim in mind, the present paper has explored the climate adaptation literature through the lenses of the institutional analysis and development framework. More specifically, the paper has explored the consideration 
climate adaptation scholars give to the various elements of that framework, distinguishing aspects that were already granted substantial attention from those ones that have so far received less focus. The analysis has identified a gap concerning biophysical conditions and physical interactions: the former feature often in merely descriptive terms; the latter are mostly neglected. Articles focus on public adaptation and collective-choice questions, whereas private adaptation and operational choice tend to be addressed by other means than institutional analysis (impact analyses, behavioural analyses, decision analyses) or under very specific perspectives (vulnerability, learning).

Filling these gaps can go either in the direction of more comprehensive analyses, striving towards a full coverage of IAD elements, or in the direction of in-depth analyses of single IAD elements. The former are currently missing due to limited interest in biophysical conditions and physical interactions. The latter are missing entirely for some narratives, or tend to cover only specific elements for other narratives.

\section{Supplementary material}

To view supplementary material for this article, please visit https://doi.org/ $10.1017 /$ S1744137417000376

\section{Acknowledgements}

We gratefully acknowledge funding by the German Federal Ministry of Education and Research, BMBF (grant agreement FKZ 03EK3523C) and by the EU (Green Win project, grant no. 642018). We also wish to thank Klaus Eisenack, the journal's editors and three anonymous reviewers for their precious comments on earlier versions of this paper.

\section{References}

Abel, N., R. Gorddard, B. Harman, A. Leitch, J. Langridge, A. Ryan and S. Heyenga (2011), 'Sea level rise, coastal development and planned retreat: analytical framework, governance principles and an Australian case study', Environmental Science \& Policy 14: 279-88.

Adger, W. N. (2003), 'Social capital, collective action, and adaptation to climate change', Economic Geography 79(4): 387-404.

Armitage, D., F. Berkes, A. Dale, E. Kocho-Schellenberg and E. Patton (2011), 'Comanagement and the co-production of knowledge: Learning to adapt in Canada's Arctic', Global Environmental Change 21: 995-1004.

Baird, J., R. Plummer, C. Haug and D. Huitema (2014), 'Learning effects of interactive decision-making processes for climate change adaptation', Global Environmental Change 27: 51-63.

Berrang-Ford, L., J. D. Ford and J. Paterson (2011), 'Are we adapting to climate change?' Global Environmental Change 21(1): 25-33. 
Berrang-Ford, L., T. Pearce and J. D. Ford (2015), 'Systematic review approaches for climate change adaptation research', Regional Environmental Change 15(5): 755-69.

Bichard, E. and A. Kazmierczak (2012), 'Are homeowners willing to adapt to and mitigate the effects of climate change?' Climatic Change 112(3-4): 633-54.

Bierbaum, R., J. B. Smith, A. Lee, M. Blair, L. Carter, F. S. C. III, P. Fleming, S. Ruffo, M. Stults, S. McNeeley, E. Wasley and L. Verduzco (2013), 'A comprehensive review of climate adaptation in the United States: more than before, but less than needed', Mitigation and Adaptation Strategies for Global Change 18: 361-406.

Biesbroek, G. R., J. E. M. Klostermann, C. J. A. M. Termeer and P. Kabat (2013), 'On the nature of barriers to climate change adaptation', Regional Environmental Change 13(5): 1119-29.

Biesbroek, G. R., R. J. Swart, T. R. Carter, C. Cowan, T. Henrichs, H. Mela, M. D. Morecroft and D. Rey (2010), 'Europe adapts to climate change: comparing national adaptation strategies', Global Environmental Change 20(3): 440-50.

Biesbroek, G. R., C. J. A. M. Termeer, J. E. M. Klostermann and P. Kabat (2014), 'Rethinking barriers to adaptation: mechanism-based explanation of impasses in the governance of an innovative adaptation measure', Global Environmental Change 26: 108-18.

Cox, M. (2012), 'Diagnosing institutional fit: a formal perspective', Ecology and Society 17(4): 54.

Cuevas, S. C. (2016), 'The interconnected nature of the challenges in mainstreaming climate change adaptation: evidence from local land use planning', Climatic Change 3(4): 66176.

Cundill, G. (2010), 'Monitoring social learning processes in adaptive comanagement: three case studies from South Africa', Ecology and Society 15(3): 28.

Denzau, A. T. and D. C. North (1994), 'Shared mental models: ideologies and institutions', Kyklos 47(1): 3-31.

Eakin, H. (2005), 'Institutional change, climate risk, and rural vulnerability: cases from central Mexico', World Development 33(11): 1923-38.

Eisenack, K., S. C. Moser, E. Hoffmann, R. J. T. Klein, C. Oberlack, A. Pechan, M. Rotter and C. J. A. M. Termeer (2014), 'Explaining and overcoming barriers to climate change adaptation', Nature Climate Change 4: 867-72.

Eisenack, K., R. Stecker, D. Reckien and E. Hoffmann (2012), 'Adaptation to climate change in the transport sector: a review of actions and actors', Mitigation Adaptation Strategies for Global Change 17(5): 451-69.

Epstein, G., J. Pittman, S. M. Alexander, S. Berdej, T. Dyck, U. Kreitmair, K. J. Raithwell, S. Villamayor-Tomas, J. M. Vogt and D. Armitage (2015), 'Institutional fit and the sustainability of social-ecological systems', Current Opinion in Environmental Sustainability 14: 34-40.

Ford, J. D., L. Berrang-Ford, A. Bunce, C. McKay, M. Irwin and T. Pearce (2015), 'The status of climate change adaptation in Africa and Asia', Regional Environmental Change 15(5): 801-14.

Ford, J. D., L. Berrang-Ford and J. Paterson (2011), 'A systematic review of observed climate change adaptation in developed nations', Climatic Change 106(2): 327-36.

Füssel, H.-M. and R. J. T. Klein (2006), 'Climate change vulnerability assessments: an evolution of conceptual thinking', Climatic Change 75(3): 301-29.

Glaas, E., A. Jonsson, M. Hjerpe and Y. Andersson-Sköld (2010), 'Managing climate change vulnerabilities: formal institutions and knowledge use as determinants of adaptive capacity at the local level in Sweden', Local Environment 15(6): 525-39. 
Grothmann, T. and A. Patt (2005), 'Adaptive capacity and human cognition: the process of individual adaptation to climate change', Global Environmental Change 15: 199-213.

Hagedorn, K. (2008), 'Particular requirements for institutional analysis in nature-related sectors', European Review of Agricultural Economics 35(3): 357-84.

Hall, P. A. and R. C. R. Taylor (1996), 'Political science and the three new institutionalisms', Political Studies 44(5): 936-57.

Harries, T. and E. Penning-Rowsell (2011), 'Victim pressure, institutional inertia and climate change adaptation: the case of flood risk', Global Environmental Change 21(1): 188-97.

Hindriks, F. and F. Guala (2015), 'Understanding institutions: replies to Aoki, Binmore, Hodgson, Searle, Smith, and Sugden', Journal of Institutional Economics 11(3): 51522.

Hinkel, J. and A. Bisaro (2014), 'A review and classification of analytical methods for climate change adaptation', WIREs Climate Change 6(2): 171-88.

Hinkel, J. and A. Bisaro (2016), 'Methodological choices in solution-oriented adaptation research: a diagnostic framework', Regional Environmental Change 16: 7-20.

Hodgson, G. M. (2015), 'On defining institutions: rules versus equilibria', Journal of Institutional Economics 11(3): 497-505.

Huntjens, P., L. Lebel, C. Pahl-Wostl, J. Camkin, R. Schulze, N. Kranz (2012), 'Institutional design propositions for the governance of adaptation to climate change in the water sector', Global Environmental Change 22: 67-81.

IPCC (2013a), 'Factsheet: What literature does the IPCC assess? Available online on (ipcc.ch). Last accessed: 8 March 2017.

IPCC (2013b), 'Principles governing IPCC work. Appendix A. Available online on (ipcc.ch). Last accessed: 8 March 2017.

Janssen, M. A., M. L. Schoon, W. Ke and K. Börner (2006), 'Scholarly networks on resilience,,vulnerability and adaptation within the human dimensions of global environmental change', Global Environmental Change 16: 240-52.

Jantarasami, L. C., J. J. Lawler and C. W. Thomas (2010), 'Institutional barriers to climate change adaptation in US National Parks and Forests', Ecology and Society 15(4): 33.

Juhola, S. and L. Westerhoff (2011), 'Challenges of adaptation to climate change across multiple scales: a case study of network governance in two European countries', Environmental Science \&o Policy 14(3): 239-47.

Kellens, W., T. Terpstra and P. D. Maeyer (2013), 'Perception and communication of flood risks: a systematic review of empirical research', Risk Analysis 33(1): 24-49.

Knight, J. (1992), Institutions and Social Conflict, Cambridge: Cambridge University Press.

Knight, J. and D. North (1997), 'Explaining economic change: the interplay between cognition and institutions', Legal Theory 3(3): 211-26.

McGinnis, M. D. (2011), 'An introduction to IAD and the language of the Ostrom Workshop: a simple guide to a complex framework', Policy Studies Journal 39(1): 169-84.

Nguyen, T. P. L., G. Seddaiu, S. G. P. Virdis, C. Tidore, M. Pasqui, and P. P. Roggero (2016), 'Perceiving to learn or learning to perceive? Understanding farmers' perceptions and adaptation to climate uncertainties', Agricultural Systems 143: 205-16.

Nielsen, J. Ø. and S. A. L. D’haen (2014), 'Asking about climate change: Reflections on methodology in qualitative climate change research published in Global Environmental Change since, 2000', Global Environmental Change 24: 402-9.

North, D. C. (1991), 'Institutions', Journal of Economic Perspectives 5(1): 97-112.

O’brien, K., S. Eriksen, L. P. Nygaard and A. Schjolden (2011), 'Why different interpretations of vulnerability matter in climate change discourses', Climate Policy 7(1): 73-88. 
Oberlack, C. (2016), 'Diagnosing institutional barriers and opportunities for adaptation to climate change', Mitigation and Adaptation Strategies for Global Change 22(5): 80538.

Ostrom, E. (1990), Governing the Commons: The Evolution of Institutions for Collective Action, Cambridge: Cambridge University Press.

Ostrom, E. (2005), Understanding Institutional Diversity, Princeton: Princeton University Press.

Ostrom, E. (2007), 'Institutional rational choice an assessment of the institutional analysis and development framework', in P. Sabatier (ed.), Theories of the Policy Process, Boulder, CO: Westview Press, pp. 21-64.

Ostrom, E. (2009), 'A general framework for analyzing sustainability of social-ecological systems', Science 325(5939): 419-22.

Ostrom, E. (2011), 'Background on the institutional analysis and development framework', Policy Studies Journal 39(1): 7-28.

Paavola, J. (2007), 'Institutions and environmental governance: a reconceptualization', Ecological Economics 63(1): 93-103.

Pahl-Wostl, C. (2007), 'Transitions towards adaptive management of water facing climate and global change', Water Resource Management 21(1): 49-62.

Pahl-Wostl, C., E. Mostert and D. Tàbara (2008), 'The growing importance of social learning in water resources management and sustainability science', Ecology and Society 13(1): 24.

Pelling, M. and C. High (2005), 'Understanding adaptation: What can social capital offer assessments of adaptive capacity?' Global Environmental Change 15(4): 308-19.

Petticrew, M. and H. Roberts (2008), 'Systematic reviews - do they "work" in informing decision-making around health inequalities?' Health Economics 3(2): 197-211.

Plummer, R., R. de Loë and D. Armitage (2012), 'A systematic review of water vulnerability assessment tools', Water Resource Management 26(15): 4327-46.

Poteete, A. R. and E. Ostrom (2008), 'Fifteen years of empirical research on collective action in natural resource management: struggling to build large- $\mathrm{N}$ databases based on qualitative research', World Development 36(1): 176-95.

Poteete, A. R., E. Ostrom and M. Janssen (2010), Working Together, Princeton: Princeton University Press.

Roggero, M. (2015), 'Adapting institutions: exploring climate adaptation through institutional economics and set relations', Ecological Economics 118: 114-22.

Seara, T., P. M. Clay and L. L. Colburn (2016), 'Perceived adaptive capacity and natural disasters: a fisheries case study', Global Environmental Change 38: 49-57.

Searle, J. R. (2005), 'What is an institution?' Journal of Institutional Economics 1(1): $1-22$.

Smit, B. and J. Wandel (2006), 'Adaptation, adaptive capacity and vulnerability', Global Environmental Change 16: 282-92.

Thackeray, S. J., T. H. Sparks, M. Frederiksen, S. Burthe, P. J. Bacon, J. R. Bell, M. S. Botham, T. M. Brereton, P. W. Bright, L. Carvalho, T. Clutton-Brock, A. Dawson, M. Edwards, J. M. Elliott, R. Harrington, D. Johns, I. D. Jones, J. T. Jones, D. I. Leech, D. B. Roy, W. Andy Scott, M. Smith, R. J. Smithers, I. J. Winfield and S. Wanless (2010), 'Trophic level asynchrony in rates of phenological change for marine, freshwater and terrestrial environments', Global Change Biology 16(12): 330-413.

Thiel, A., C. Schleyer, J. Hinkel, M. Schlüter, K. Hagedorn, A. Bisaro, I. Bobojonov and A. Hamidov (2016), 'Transferring Williamson's discriminating alignment to the 
analysis of environmental governance of social-ecological interdependence', Ecological Economics 128: 159-68.

Thiel, A., C. Schleyer and T. Plieninger (2012), 'Wolves are mobile, while fruit trees are not! How characteristics of resources and supranational regulatory frameworks shape the provision of biodiversity and ecosystem services in Germany', Environmental Policy and Governance. Published online in Wiley Online Library.

Vatn, A. (2005), Institutions and the Environment, Cheltenham: Edward Elgar.

Villamayor-Tomas, S. (2017), 'Disturbance features, coordination and cooperation: an institutional economics analysis of adaptations by water user associations in Spain', Journal of Institutional Economics (submitted).

Vogt, J. M., G. B. Epstein; S. K. Mincey, B. C. Fischer and P. McCord (2015), 'Putting the "E" in SES: unpacking the ecology in the Ostrom social-ecological system framework', Ecology and Society, 20(1): 55.

Williamson, O. E. (2000), 'The New Institutional Economics: Taking Stock, Looking Ahead', Journal of Economic Literature 38: 595-613.

Young, O. (2002), The Institutional Dimensions of Environmental Change: Fit, Interplay, and Scale, Cambridge: The MIT Press.

Zhang, Y. W., A. D. Hagerman and B. A. McCarl (2013), 'How climate factors influence the spatial distribution of Texas cattle breeds', Climatic Change 118(2): 183-95. 